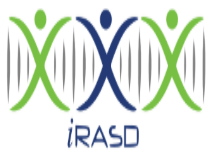

iRASD Journal of Management

Volume 4, Number 1, 2022, Pages 17 - 25

Journal Homepage:

https://journals.internationalrasd.org/index.php/jom
RASD

JOURNAL OF MANAGEMENT

\title{
Green Human Resource Practices: A Sustainable Approach To Increase Employee Performance
}

\author{
Ali Junaid Khan ${ }^{1}$, Muhammad Akbar Ali Ansari², Tanveer Ahmed ${ }^{3}$, Areeba Athar Malik ${ }^{4}$ \\ ${ }^{1}$ Institute of Business Management \& Administrative Sciences, The Islamia University of Bahawalpur, Pakistan. \\ Email: Junaaidkhan@yahoo.com \\ ${ }^{2}$ Department of Commerce, The Islamia University of Bahawalpur, Pakistan. Email: Makbar.ali@iub.edu.pk \\ ${ }^{3}$ Department of Environmental Management, National College of Business Administration \& Economics, Lahore, \\ Pakistan. Email: Ranatanveer786@gmail.com \\ ${ }^{4}$ Department of Applied Psychology, The Islamia University of Bahawalpur, Pakistan. Email: Areeba_leo@live.com
}

\begin{tabular}{|c|c|}
\hline \multicolumn{2}{|l|}{ ARTICLE INFO } \\
\hline Article History: & \\
\hline Received: & December 17, 2021 \\
\hline Revised: & January 21,2022 \\
\hline Accepted: & January 22,2022 \\
\hline Available Online: & January 25,2022 \\
\hline
\end{tabular}

\section{Keywords:}

Green (HRM) Practices

Recruitment

Training

Reward

Employee Performance

Small Medium Enterprise (SME) sector of Pakistan

\begin{abstract}
The research is explanatory about Green Human Resource Management (GHRM) and its Impact on Employee Performance in Pakistan's Small Medium Enterprise sector. PLS Software has been used for statistical research analysis, discriminant validity, loading factors, average variance executor, composite reliability, predictive value, and bootstrapping value from 308 small-medium enterprises (SME) employees. Data has taken as a questionnaire through Google form. The empirical study has explained the positive relationship of Green (HRM) to Employee Performance in SME sector. The previous studies have also determined about positive relation of these variables. Recruitment, training and reward have been selected and explained in research and have clear objectives of the investigation. The results showed a positive relationship between GHRM and employee performance. The finding of this paper has several implications for government officials and policy makers of SME sector to provide the framework to support employee green behavior.
\end{abstract}

(c) 2022 The Authors, Published by iRASD. This is an Open Access article under the Creative Common Attribution Non-Commercial 4.0

Corresponding Author's Email: Junaaidkhan@yahoo.com

\section{Introduction}

After the United Nations Brundtland Report (also known as "Our Common Future") was issued in the late 1980s, sustainability became a hot topic. The study explored "development that meets current needs without compromising future generations' ability to meet their own" (p. 41). From this definition, the term "Organizational sustainability" was developed. Since for-profit organizations have historically addressed this issue, corporate sustainability encompasses ecological concerns and social responsibility and the integration of economic activities concerning the natural and social environment (Linnenluecke \& Griffiths, 2010).

A company's supply chain, manufacturing process, production process, waste management and organizational culture, and employee behaviour are just a few examples of how "greening" an organization may influence all of these areas. After two decades of mainstream sustainability and environmental consciousness, the problem of human resource management has become an important strategic instrument for greening an organization and, in turn, the economy and society at large. Wehrmeyer (1996), employees are essential to a company's success or failure when it comes to taking a sustainable approach to its operations. 
Due to their significant contribution to economic development, small and mediumsized enterprises are typically the principal drivers of long-run economic growth. Economic progress is stymied by SMEs failure to operate regularly (Azarloo, Eshghiaraghi, Salehi, Habibpoor, \& Jahangiri, 2017). SME's account for about $90 \%$ of all businesses in Pakistan (www.smeda.org). SMEs generate another $40 \%$ of the GDP. On the other hand, Pakistan's SMEs are under pressure due to poor performance. A fall in the performance of SMEs has been cited as one of the primary reasons for Pakistan's drop to 138th rank out of 189 countries on the business index (Lakhan, Mumtaz, Keeryo, \& Dayo, 2021). Due to many limitations, sustained growth is challenging for Pakistani SMEs (Wahga, Blundel, \& Schaefer, 2015). These SMEs encounters many entrepreneurial-related obstacles (Hussain, Khan, \& Shah, 2015). All the variables has negative effect on performance.

Moreover, a reduction in the performance of SMEs limits work prospects for people lacking an entrepreneurial spirit. As a result, it aided in the growth of poverty. As a result, a fall in the performance of SMEs in Pakistan is a cause for concern. HRM. has become necessary since the $19^{\text {th }}$ Century, and companies are using great strategies to improve employee performance in the SME sector. Some companies think that employees are precious assets, and it must be essential to improve their working style in manner. (Dumont et al., 2017). In Pakistan, Due to economic conditions, HRM practices are slightly slow, but companies use unique strategies to improve day-by-day work. And this made them on job training and assessment by proper behaviour ( Zhu \& Chen, 2015). Green Human Resource management has been introduced in Pakistan, and this strategy contains more skill learning in less time and improves employee work perforce by recruitment methods and incentives, benefits and allowance made them encourage and feel free to work. (Saeed, Afsar, Hafeez, S., \& Tahir, 2019).

Small and medium-sized enterprises (SMEs) need quality human resources to manage their businesses. The most brilliant human resources professionals choose to work for major corporations. Workers today consider how the company's reputation ties to the company's care for the environment when considering which job to choose. In this regard, SMEs must design a human resource management strategy that is based on the environment and includes planning, hiring, developing, and managing its human resources in order for them to become a source of business value added in their respective industries. Accordingly, the goal of this study was to investigate and develop a framework for the practise of Green Human Resources Management in Small and Medium-Sized Enterprises (SMEs) in Pakistan.

\section{Literature Review 2.1. Employee Performance}

Prior study has placed a premium on the overall efficacy of an organization. Each firm, to succeed, must have a competitive advantage. Considerable research on the numerous variables, dimensions, and causes of the performance of organization has been done, all with a large emphasis (Fernando \& Bandara, 2020; Khan \& Iqbal, 2020). Researchers are not agree on the most effective way to quantify the performance (Posthuma, Campion, Masimova, \& Campion, 2013). It is frequently measured in one of two ways: in monetary terms or non-monetary terms. Khan and Iqbal (2020) assert that nonfinancial or economic performance measurements might bolster a company's significance.

The survival and success of small businesses are both reliant on their ability to execute. Moreover, due to the slow economy, SMEs have several challenges when it comes to reaching a reasonable level of performance (Wahga et al., 2015). The resourcebased view (RBV) holds that an organization's performance depends on its internal resources like human resources. Effective human resources are the basics upon which successful businesses are founded. (Umrani, 2016). Employees' opinions about the characteristics of their jobs, according to research, have an impact on their work habits (Yusoff et al., 2018). Certain characteristics of work, such as pride, engagement, and recognition, can have an impact on how individuals regard their jobs and, as a result, their level of enjoyment in their jobs (Arnett et al., 2002). The Job Characteristics Theory identifies a number of fundamental job characteristics, including skill diversity, task identity, task significance, autonomy, and feedback, as being characteristics that may lead people to experience a range of various sorts of emotional responses. Enhancing a person's 
intrinsic motivation by embracing various work components might result in higher employee performance organizational outcomes (Khan \& Iqbal 2020).

When firms utilise human resource management to foster the growth and development of environmentally friendly workers, such as those who are employed and rewarded accordingly, it helps them perform better as a whole. As a company's backbone, employees' pro-environmentary attitudes and actions contribute to the overall environmental performance of the organisation (Kim et al., 2019).

\subsection{Recruitment}

Recruiting high-quality personnel via environmental efforts and a green image is adopted by German corporations such as Siemens, Bayer, and Mannesmann. According to the company, Rover Group automobiles include environmental requirements and certifications into all job descriptions in the United Kingdom (Wehrmeyer, 1996). Green job descriptions that contain ecological considerations are becoming more common in the recruitment approach for new employees. Green recruitment is the process of selecting employees who have the knowledge, skills, methodologies, and habits that are compatible with an organization's environmental management systems, also known as environmental compliance. According to Wehrmeyer (1996), effective environmental management may be facilitated by ensuring that new employees are familiar with an organization's ecological culture and capable of preserving its ecological principles when they first join.

Using a green recruiting strategy, a firm may emphasize on the importance of environment while also make it a fundamental component of organization. Aside from that, the new hires are enthusiastic and, to a lesser extent, impassioned about the prospect of a work for an ecologically friendly "green" organization. "Recruiting" employees with a green bent of mind enables businesses to quickly recruit professionals already familiar with sustainable processes and essentials such as conservation, recycling, , and creating a more rational working environment. In the study on the impact of environmental standards of a business on employee recruitment, Grolleau et al. (2012) found that a company's environmental commitment helps to the company's profile. Their first survey observed that professionals were more interested in its ecological strategy than the general public.

\subsection{Training}

Training in environmental management educate employees on the importance of ecological management, train them in energy-saving and waste-reduction strategies, raise environmental awareness, and provide employees with opportunities to participate in environmental problem-solving (Zoogah, 2011). Due to green training and development, employees become more aware of ecological management's numerous elements and relevance. Several conservation measures, like waste management inside a firm, aid them in adopting. Furthermore, it improves an employee's capacity to deal with a wide range of environmental challenges as they arise. Ramus \& Kelmer (2007) concluded from a survey of managers on best management practices that ecological training and education, as well as the establishment of a positive environmental culture in which employees feel a sense of ownership over environmental outcomes, are the most critical human resource management actions that facilitates the goals achievement of environment. According to Ahmad (2015) promotes green training on the one hand and assists enterprises in developing eco-friendly managers who may indulge without worry on the other hand will benefit all parties concerned.

\subsection{Reward}

Employees are recognized and paid for their efforts through the critical human resource management methods of incentives and pay. When it comes to aligning an individual's interests with the company's interests, these human resource methods are the most successful. Furthermore, we believe that incentives and rewards can impact workers' capacity to give their all at work and expend the maximum amount of effort feasible to accomplish corporate goals. 
According to the Green HRM perspective, employee incentives and reward are two strategies that may be used to encourage environmental initiatives in organizations. By the similar study done by Ahmad (2015) when employees were given money to participate in activities connected to ecological responsibility, their involvement in environmental management programs increased. Berrone and Gomez-Mejia (2009) the impact of green incentives and remuneration was shown to the greatest extent. They observed that organizations with environmentally performance paid their CEOs higher than organizations with non friendly environment. They discovered that increased pollution avoidance success was associated with improved long-term company performance commensurate with remuneration. According to a review of the literature, CEOs are compelled are used the green human resources practices to optimism earnings and short-term outcomes (Benz \& Frey, 2007).

However, they pay and incentives drive green behavior in businesses, it can not be completely free of errors. Due to the problems in fairly and accurately evaluating environmental performance and behaviors, there is developing an effective monetary reward may be challenging and the challenges in accurately and fairly measuring ecological performance. Consequently, we agree with Gupta (2018) that businesses must develop energy-efficient processes and products and provide reward to encourage its use. There is an argument that if there is green reward and compensation systems are linked with the human resource management process, organizations may promote a more environmentally conscious culture. Managers may encourage workers to adopt green behaviors and practices in the workplace by adding components of sustainable management into employee remuneration packages. Additionally, managers should urge staff to contribute particular green ideas related to their occupations, which can subsequently be included in the year's goals through collaborative decision-making. Attaining these goals would serve as the foundation for obtaining advantages.

\section{Conceptual Framework}

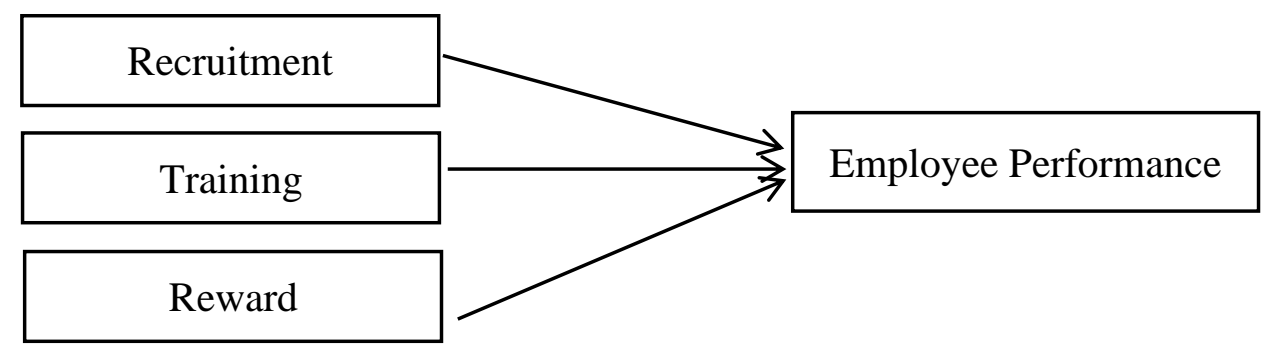

Figure 1: Conceptual Framework

\section{Hypotheses}

H1: Green recruitment practice is positively related to employee performance in the smallmedium enterprise (SME) sector in Pakistan

H2: Green training practice is positively related to employee performance in the smallmedium enterprise (SME) sector in Pakistan

H3: Green reward practice is positively related to employee performance in the smallmedium enterprise (SME) sector in Pakistan

\subsection{Methodology}

To test the theoretical model, data was collected from employees of SMEs in Pakistan. Quantitative research was undertaken to determine factors associated with employee performance. The study's population comprises employees in Pakistan's SME sector. We administered a questionnaire to the target population from June to August 2021. This study used a questionnaire to elicit rapid replies at a certain period. We contacted the company's human resources department and informed them of the reason for the data collection. SMEs employees who were easily reachable were surveyed using the conveyance sample technique, and data was gathered from them. According to Comrey and Lee's 
approach, the sample size was calculated (1992). As stated by Comrey and Lee (1992), a sample size of 50 respondents is insufficient, a sample size of 100 respondents is even more insufficient, a sample size of 200 respondents is satisfactory, a sample size of 300 is adequate, a sample size of 500 is excellent, and a sample size of 1000 respondents is enormous. The questions were given by email in order to keep up with the Covid-19 distribution. It was asked that the questionnaire be sent through email to employees by the human resources departments of various SMEs. There were a total of 500 questions sent out by email, with 330 of them being returned and 308 of them being included in the final analysis.

\subsection{Measures}

The relevance of each variable has been assessed on a five-point Likert scale, with higher scores representing more significance. The scales were adopted from studies that have been previously utilised and well-researched. The questionnaire, which was originally created in English, has undergone multiple revisions since its inception. The amount of green HRM was measured using the same scale as in the study conducted by Khan et al., 2021. The respondents were asked to indicated how GHRM practices are implemented in their organization. The study conducted by Ramos et al., 2019 was used to collect the data on individual employee performance.

\section{Data analysis and results \\ 4.1. Measurement model}

Smart PLS is a piece of statistical software that is intended to assist researchers in the analysis of data, notably in the field of social sciences and psychology.

\section{Table 1}

\section{Estimation Results}

\begin{tabular}{|c|c|c|c|}
\hline 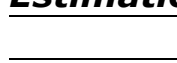 & Loading & AVE & CR \\
\hline EP1 & 0.832 & 0.646 & 0.965 \\
\hline EP10 & 0.828 & & \\
\hline EP11 & 0.812 & & \\
\hline EP12 & 0.783 & & \\
\hline EP13 & 0.837 & & \\
\hline EP14 & 0.806 & & \\
\hline EP15 & 0.793 & & \\
\hline EP2 & 0.755 & & \\
\hline EP3 & 0.734 & & \\
\hline EP4 & 0.771 & & \\
\hline EP5 & 0.766 & & \\
\hline EP6 & 0.822 & & \\
\hline EP7 & 0.814 & & \\
\hline EP8 & 0.838 & & \\
\hline EP9 & 0.853 & & \\
\hline RGHR1 & 0.831 & 0.675 & 0.912 \\
\hline RGHR2 & 0.831 & & \\
\hline RGHR3 & 0.826 & & \\
\hline RGHR4 & 0.856 & & \\
\hline RGHR5 & 0.761 & & \\
\hline RWGHR1 & 0.767 & 0.66 & 0.906 \\
\hline RWGHR2 & 0.782 & & \\
\hline RWGHR3 & 0.862 & & \\
\hline RWGHR4 & 0.8 & & \\
\hline RWGHR5 & 0.848 & & \\
\hline TGHR1 & 0.746 & 0.674 & 0.912 \\
\hline TGHR2 & 0.79 & & \\
\hline TGHR3 & 0.868 & & \\
\hline TGHR4 & 0.855 & & \\
\hline TGHR5 & 0.84 & & \\
\hline
\end{tabular}


The SmarPLS 3 was used to evaluate the measurement model. As part of analysis, the AVE, factor loading, composite reliability (CR), and Cronbach's alpha were all assessed to see how well they worked (Ringle, Da Silva, \& Bido, 2015). Specifically, Alpha, CR, and AVE are all recommended to be larger than or equal to 0.6 , according to Hair, Hollingsworth, Randolph, and Chong (2017). In Table 1, it can be observed that all of the numbers are greater than a preset cutoff limit. Which indicates that composite reliabilite and convergent validity has been achieved.

The $R^{2}$ value is also significant. Which represent that 94.7 percenet increase in employee performance is due to green HR practices of recruitment, training and reward.

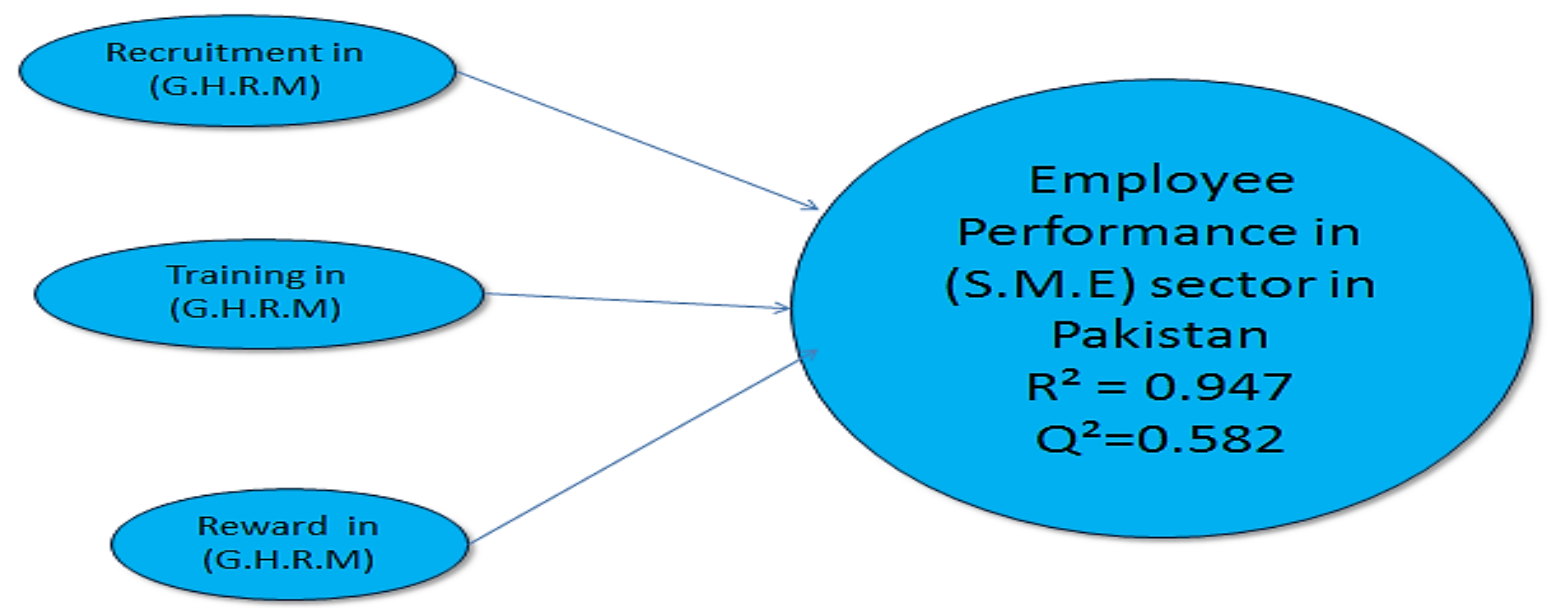

Figure 2

\subsection{Structural Model}

The researcher must ascertain the coefficients' statistical significance. Alternatively, the term "bootstrapping" may refer to any test or metric that employs random sampling with replacement. Bootstrapping permits accurate measurements such as bias, variance, confidence intervals, prediction error, or comparable measures to sample estimates. This approach allows the estimation of the sample distribution of virtually any statistic using random sampling methods. Table 2 illustrate the formalized process for determining the sample mean (M), standard deviation (STDEV), t-values, $\mathrm{p}$-values, and decision. As it can be seen in the below table, the t-value is above 1.96, and positive values indicate a positive relationship. Hence, all the proposed hypotheses are accepted and show a strong positive relationship between GHRM practises and employee performance.

Table. 2

Hypothesis Testing

\begin{tabular}{|c|c|c|c|c|c|c|c|}
\hline \multicolumn{2}{|c|}{ Hypothesis } & \begin{tabular}{|l}
$\begin{array}{l}\text { Original } \\
\text { Sample (0) }\end{array}$ \\
$->0.104$
\end{tabular} & \multirow{2}{*}{$\begin{array}{l}\begin{array}{l}\text { Sample } \\
\text { Mean (M) }\end{array} \\
0.106\end{array}$} & \multirow{2}{*}{$\begin{array}{l}\begin{array}{l}\text { Standard } \\
\text { Deviation } \\
\text { (STDEV) }\end{array} \\
0.041\end{array}$} & \multirow{2}{*}{$\begin{array}{l}\mathbf{T} \\
2.51\end{array}$} & \multirow{2}{*}{$\begin{array}{l}\text { P Values } \\
0.012\end{array}$} & \multirow{2}{*}{$\begin{array}{l}\text { Decision } \\
\text { Supported }\end{array}$} \\
\hline$\overline{\mathrm{H1}}$ & $\begin{array}{lc}\text { Recruitment } & \text { (G.HRM) } \\
\text { Employee } & \text { Performar } \\
\text { in (SME) } & \text { sector } \\
\text { Pakistan } & \end{array}$ & $\begin{array}{l}->0.104 \\
\text { nce } \\
\text { of }\end{array}$ & & & & & \\
\hline H2 & $\begin{array}{ll}\text { Reward } & \text { (G.HRM) } \\
\text { Employee } & \text { Performar } \\
\text { in (SME) } & \text { sector } \\
\text { Pakistan } & \end{array}$ & $\begin{array}{l}->0.471 \\
\text { nce } \\
\text { of }\end{array}$ & 0.467 & 0.083 & 5.65 & 0.000 & Supported \\
\hline H3 & $\begin{array}{lc}\text { Training } & \text { (G.HRM) } \\
\text { Employee } & \text { Performar } \\
\text { in (SME) } & \text { sector } \\
\text { Pakistan } & \\
\end{array}$ & $\begin{array}{l}->0.418 \\
\text { nce } \\
\text { of }\end{array}$ & 0.42 & 0.084 & 4.954 & 0.000 & Supported \\
\hline
\end{tabular}




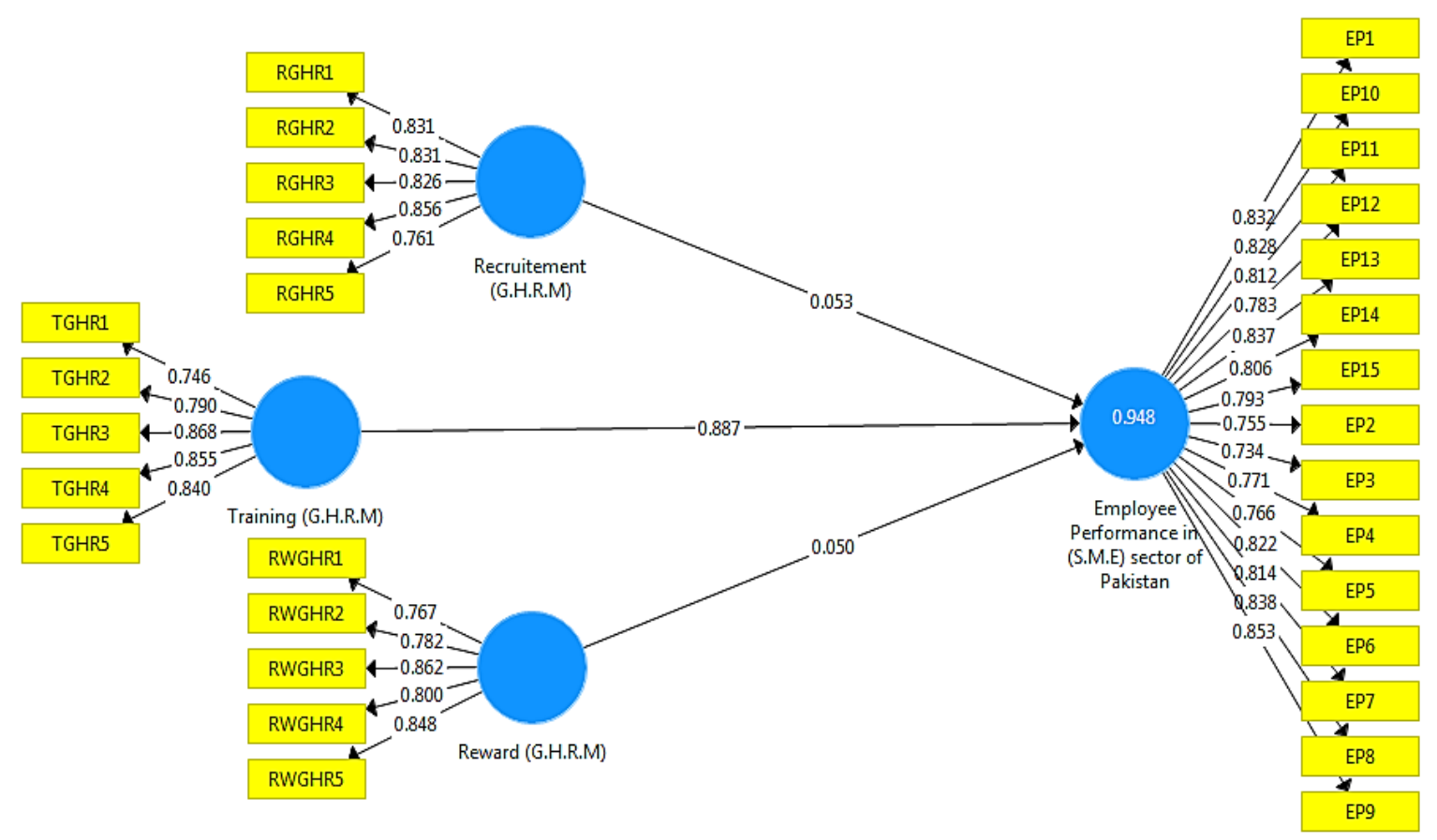

Figure 3: SEM Estimates

\section{Discussion}

Employee performance encourages employees to develop their professional abilities inside or for the organization in order to achieve the basic objective. Balancing the company's environmental concerns with the obligations of government legislation is a challenge in green employee performance. Furthermore, it highlights the need for environmental stewardship in daily living. Epstein and Roy (1997) found in their study that by incorporating environmental performance into project management systems, human resource managers may help prevent ecological damage. Several companies are developing enterprise-wide environmental performance standards and green information systems/audits in order to acquire significant data on environmental performance.

The major goal of the study was to establish whether there is a link between green (human resource management) practises and employee performance in small and mediumsized enterprises (SMEs) in Pakistan. The findings are consistent with prior study, which revealed that green HR practises have a substantial impact on employee commitment and satisfaction, which in turn leads to improved employee performance (Khan, Tufail \& Ali, 2021). In addition, if the employees' green behaviour is taken into consideration throughout the recruiting process, it is more likely that the employees will exhibit green behaviour after being hired. Similarly, employees can be trained on the benefits of green human resource practises, and finally, by linking rewards with the adoption of green human resource practises, SMEs can easily improve employee performance, which would also be beneficial for improving organisational performance. An abundance of prior research has demonstrated that improved employee performance results in improved organisational performance (Khan et al., 2020, 2021). The conclusions of these studies have a variety of ramifications for small and medium-sized enterprises (SMEs) as well as policymakers at all levels of government. As in this Era, a strong focus is placed on environmentally friendly and sustainable techniques. The present administration of Pakistan has also made a number of initiatives to ensure that the country's long-term sustainable and development objectives are met.

\section{Managerial Implications}

The outcomes of this study have a wide variety of potential applications in business and management. The use of green human resource management in an organization's overall performance as well as employee performance may contribute to the achievement of the Pakistani government's Climate Action Vision. Creating an environmental operations 
framework is the first step in applying green human resource management methods in a corporate setting. It is necessary to do this by making the organization's commitment to environmental conservation the driving force behind the implementation of green initiatives. The management of a firm must demonstrate that environmental sustainability is a top priority by defining corporate goals that include environmental sustainability as a component of their overall mission. When middle and human resource managers pay attention to their employees' green practises, they have the potential to enhance the environmental performance of their organisations. Employees serve as the backbone of organisations and a significant source of competitive advantage. By implementing green human resource management practises, such as the recruitment of employees who exhibit green behaviour, training employees, and rewarding employees for their environmental performance, it is possible to increase the performance of SMEs in Pakistan.

\subsection{Limitation and Future Direction}

The study's findings suggest that green (human resource management) techniques have an effect on employee performance in the SMEs sector of Pakistan's Small Medium Enterprises. Thus, this study is especially pertinent for individuals involved in the operation of Pakistan's online websites. They are encouraged to include flexibility in their recruitment, morality, training, selection, and reward strategies in order to offer high-quality.

For these reasons, we conclude that green recruiting enables firms to differentiate themselves from the competition, increasing their chances of attracting and retaining applicants. To contribute to the current green trend, we advocate for hiring practices that are environmentally beneficial. Further study should be performed to address concerns about the green employer's commitment to environmental goals and to ascertain how potential job prospects perceive or grade the green employer on the sustainability criteria mentioned. Have they determined that a company's use of green job descriptions, ecofriendly venues, paperless interviews, and other activities in their recruiting portfolio is a success? Is it feasible for new workers to familiarize themselves with the company's environmental policies and commitments prior to starting work? Investigating and resolving these issues will assist new workers in adhering to the company's green policies while also collaborating with management to design new green policies that meet the company's objectives.

\section{References}

Ahmad, S. (2015). Green human resource management: Policies and practices. Cogent business \& management, 2(1), 1030817.

Arnett, D.B., Laverie, D.A. and McLane, C. (2002). Using job satisfaction and pride as internal marketing tools. Cornell Hotel and Restaurant Administration Quarterly, 43 (2), 87-96.

Azarloo, M., Eshghiaraghi, M., Salehi, S. Y., Habibpoor, V., \& Jahangiri, M. (2017). Factors Affecting Technological Entrepreneurship and Innovation in Small and Medium Enterprises (SMEs) and its Role in Countries' Economic Development.

Benz, M., \& Frey, B. S. (2007). Corporate governance: What can we learn from public governance?. Academy of Management Review, 32(1), 92-104.

Berrone, P., \& Gomez-Mejia, L. R. (2009). Environmental performance and executive compensation: An integrated agency-institutional perspective. Academy of Management Journal, 52(1), 103-126.

Comrey, A., \& Lee, H. (1992). Interpretation and application of factor analytic results. Comrey AL, Lee HB. A first course in factor analysis, 2, 1992.

Epstein, M. J., \& Roy, M. J. (1997). Using ISO 14000 for improved organizational learning and environmental management. Environmental Quality Management, 7(1), 21-30.

Fernando, M., \& Bandara, R. (2020). Towards virtuous and ethical organisational performance in the context of corruption: A case study in the public sector. Public Administration and Development, 40(3), 196-204.

Gupta, H. (2018). Assessing organizations performance on the basis of GHRM practices using BWM and Fuzzy TOPSIS. Journal of environmental management, 226, 201216. 
Grolleau, G., Mzoughi, N., \& Pekovic, S. (2012). Green not (only) for profit: An empirical examination of the effect of environmental-related standards on employees' recruitment. Resource and Energy Economics, 34(1), 74-92.

Hair, J., Hollingsworth, C. L., Randolph, A. B., \& Chong, A. Y. L. (2017). An updated and expanded assessment of PLS-SEM in information systems research. Industrial Management \& Data Systems.

Hussain, J., Khan, A., \& Shah, F. A. (2015). The Impacts of Entrepreneurial Orientation on Organizational Performance: Study of Pakistani SMEs. Sarhad Journal of Management Sciences, 1(01), 52-64.

Dumont, J., Shen, J., \& Deng, X. (2017). Effects of green HRM practices on employee workplace green behavior: The role of psychological green climate and employee green values. Human resource management, 56(4), 613-627.

Khan, A. J., \& Iqbal, J. (2020). Do High Performance Work Practices Increase the Organizational Performance of Public Sector Companies? An Investigation of Mediation Mechanism. Pakistan Journal of Social Sciences (PJSS), 40(2), 1007-1021.

Khan, A. J., Shah, S. Z. A., Bashir, F., \& Iqbal, J. (2021). Antecedents and Consequences of Green Human Resource Management in Oil and Gas Companies of Pakistan. Sustainable Business and Society in Emerging Economies, 3(3), 339-351.

Khan, A. J., Tufail, S., \& Ali, A. (2021). Factors Affecting Performance of Small \& Medium Enterprises: The Mediating Role of Knowledge Management. Pakistan Journal of $\begin{array}{llll}\text { Humanities \& Social } & \text { Sciences, }\end{array}$ doi:https://doi.org/10.52131/pjhss.2021.0902.0129

Lakhan, A. B., Mumtaz, J., Keeryo, Z. A., \& Dayo, S. A. (2021). EASE OF DOING BUSINESS IN PAKISTAN. PalArch's Journal of Archaeology of Egypt/Egyptology, 18(08), 49284934.

Linnenluecke, M. K., \& Griffiths, A. (2010). Corporate sustainability and organizational culture. Journal of world business, 45(4), 357-366.

Posthuma, R. A., Campion, M. C., Masimova, M., \& Campion, M. A. (2013). A high performance work practices taxonomy: Integrating the literature and directing future research. Journal of Management, 39(5), 1184-1220.

Ramus, A. C., \& Kelmer, A. C. (2007). Corporate greening through prosocial extrarole behaviours-A conceptual framework for employee motivation. Business Strategy Environment, 16, 554-570.

Ramos-Villagrasa, P. J., Barrada, J. R., Fernández-del-Río, E., \& Koopmans, L. (2019). Assessing job performance using brief self-report scales: The case of the individual work performance questionnaire (No. ART-2019-121928).

Ringle, C., Da Silva, D., \& Bido, D. (2015). Structural equation modeling with the SmartPLS. Bido, D., da Silva, D., \& Ringle, C.(2014). Structural Equation Modeling with the Smartpls. Brazilian Journal Of Marketing, 13(2).

Saeed, B. B., Afsar, B., Hafeez, S., S., K., \& Tahir, M. (2019). Promoting employee's proenvironmental. Corporative Socope Responsibility Environment Managment, 26, 424-438.

Umrani, W. A. (2016). Moderating effect of organizational culture on the relationship between corporate entrepreneurship and business performance in Pakistan's banking sector. Universiti Utara Malaysia, Kedah Darul Aman, Malaysia.

Wahga, A., Blundel, R., \& Schaefer, A. (2015). Human capital and environmental engagement of SMEs in Pakistan: A comparative analysis of the leather industry.

Wehrmeyer, W. (1996), Greening People - Human Resources and Environmental Management, Sheffield, England: Greenleaf Publishing

Yusoff, Y.M., Nejati, M., Kee, D.M.H. and Amran, A. (2018). Linking green human resource management practices to environmental performance in hotel industry. Global Business Review, 21 (3), 1-18, doi: 10.1177/0972150918779294.

Zhu, Y. Q., \& Chen, H. G. (2015). Social media and human need satisfaction: Implications for social media marketing. Busienss Horizon, 4, 335-345.

Zoogah, D. B. (2011). The dynamics of Green HRM behaviors: A cognitive social information processing approach. German Journal of Human Resource Management, 25(2), 117139. 